\title{
Delayed-onset bleb-associated endophthalmitis: presentation and outcome by culture result
}

This article was published in the following Dove Press journal:

Clinical Ophthalmology

I June 201 I

Number of times this article has been viewed

\section{David J Jacobs \\ Theodore Leng \\ Harry W Flynn Jr \\ Wei Shi \\ Darlene Miller \\ Steven J Gedde}

Department of Ophthalmology, Bascom Palmer Eye Institute, Miller School of Medicine, University of Miami, FL, USA Bascom Palmer Eye Institute, 900 NW

I7th St, Miami, FL 33I36, USA

$\mathrm{Tel}+\mathrm{I} 3053266000$

Fax + I 305326 6I47

Email jacobs.retina@gmail.com
Correspondence: David J Jacobs

Purpose: To determine how culture results are associated with clinical presentations and outcomes in delayed-onset bleb-associated endophthalmitis (BAE).

Methods: Retrospective consecutive case series of BAE at Bascom Palmer Eye Institute between January 1, 1996 and December 31, 2009. All patients had prior glaucoma filtering surgery. BAE was defined as intraocular infection with vitreous involvement receiving treatment with intravitreal antibiotics. Visual acuity (VA) outcomes and other clinical data were grouped by culture result and compared using the 2-sided Student's $t$-test.

Main outcome measure: Mean logMAR change at 3 months after treatment (3-month $\log$ MARA).

Results: Eighty-six eyes of 85 patients were identified. Two eyes were primarily eviscerated. Fifty-three (63\%) eyes were culture-positive with the following organisms: Streptococcus, 21 (25\%); coagulase-negative Staphylococcus, 9 (11\%); Enterococcus, 6 (7\%); Gram-negative, 15 (18\%); Moraxella, 8 (10\%); Pseudomonas, 3 (4\%); and Serratia, 3 (4\%). Presenting $\log$ MAR VA: culture-positive worse than culture-negative cases $(2.45$ vs $2.19, P=0.05)$. Presenting intraocular pressure (IOP): culture-positive higher than culture-negative cases (24 mmHg vs $14 \mathrm{mmHg}, P=0.002$ ). Poor presenting view of the fundus: Streptococcus worse than coagulase-negative Staphylococcus cases (90\% vs 44\%, $P=0.006$ ), Pseudomonas and Serratia worse than Moraxella cases $(100 \%$ vs $50 \%, P=0.04)$. Three month logMAR $\Delta$ : culture-positive worse than culture-negative cases (1.03 vs $0.43, P=0.02)$, Streptococcus worse than coagulase-negative Staphylococcus cases (1.44 vs $0.31, P=0.004)$, Pseudomonas and Serratia worse than coagulase-negative Staphylococcus cases ( 2.41 vs $0.31, P=0.001)$, Pseudomonas and Serratia worse than Moraxella cases (2.41 vs $0.04, P=0.001)$. A culture result of Streptococcus or Serratia was present in 6 of 7 eyes that received an additional treatment of enucleation or evisceration $(P=0.01)$.

Conclusion: Culture-positive cases were associated with worse presenting VA, higher presenting IOP, and worse VA outcomes than culture-negative cases. Streptococcus, Pseudomonas, and Serratia cases were associated with poor presenting view of the fundus and worse VA outcomes than coagulase-negative Staphylococcus and Moraxella cases.

Keywords: endophthalmitis, bleb-associated endophthalmitis, trabeculectomy, culture results

\section{Introduction}

Visual acuity (VA) outcomes after treatment of delayed-onset bleb-associated endophthalmitis (BAE) are poor. ${ }^{1-10}$ Only $22 \%-67 \%$ of eyes with BAE achieve a VA outcome of 20/400 or better. The most frequent causative organisms isolated include Streptococcus sp. and Gram-negative organisms in 31\%-57\% and 15\%-32\% of cases, respectively. ${ }^{1-6}$ 
The association between culture results and VA outcomes has been addressed in small case series. ${ }^{1-6}$ In one study there was no significant difference between VA outcomes of eyes with Streptococcus sp., non-Streptococcus Gram-positive organisms, and Gram-negative organisms. ${ }^{2}$ Another study showed no significant difference between VA outcomes of eyes with Streptococcus and Staphylococcus sp. ${ }^{3}$ Others reported VA outcomes for eyes with Streptococcus sp. and non-Streptococcus organisms but did not perform a comparative analysis. ${ }^{4-6}$ The inability to identify a significant association between VA outcomes and culture result may be due to the relatively small number of reported BAE cases and the pre-existing ocular disease in these patients.

It is also unclear if the clinical presentation of BAE differs by culture result. Presently no studies have reported presenting clinical information (eg, intraocular pressure, presence of hypopyon, view of the fundus) by culture result. The purpose of the current study is to determine how culture results are associated with clinical presentations and outcomes in BAE by performing a comparative analysis within a large case series.

\section{Methods}

The study protocol was approved by the Institutional Review Board of the University of Miami Miller School of Medicine Subcommittee for the Protection of Human Subjects in Research. The medical records and microbiologic records of all patients treated for BAE at Bascom Palmer Eye Institute (BPEI) between January 1, 1996 and December 31, 2009 were reviewed. All patients had prior glaucoma filtering surgery. BAE was defined as intraocular infection with vitreous involvement receiving treatment with intravitreal antibiotics. Patients with tube shunts as the filtering mechanism, bleb infection only (no posterior inflammation), onset within 1 month of glaucoma surgery, and inadvertent filtering blebs after cataract surgery were excluded. Clinical history and presentation, treatment, intraocular culture data, VA outcomes, and factors affecting VA were recorded. The current study included clinical information from the series of 71 eyes treated at BPEI between January 1, 1996 and July 1,2008 , which has been reported previously. ${ }^{1}$

Snellen VAs were converted to $\log$ MAR equivalents for statistical analysis; VAs of hand motion, light perception, and no light perception were assigned logMAR values of 2.6, 3, and 4 respectively. Change in VA was determined by comparing the last recorded VA before the onset of endophthalmitis with VA at 3 months. The mean $\log M A R$ change at 3 months after presentation (3-month $\log$ MAR $\Delta$ ) and other clinical data were grouped by culture result and compared using the 2 -sided Student's $t$-test. A $P$-value of $\leq 0.05$ was considered statistically significant.

\section{Results}

Eighty-six eyes of 85 patients were identified. Two eyes were primarily eviscerated. Intraocular culture results were positive in 53 of 84 eyes, $63 \%$ Streptococcus sp. and Gram-negative organisms were the most frequent isolates, accounting for $25 \%$ and $18 \%$ of cases respectively. In five eyes, two organisms were isolated. All isolated organisms were sensitive to the intravitreal antibiotics clinically administered which included Vancomycin and Ceftazidime in 77 eyes, 92\%, Vancomycin and Amikacin in two eyes, Vancomycin and Gentamicin in one eye, Vancomycin alone in two eyes, Ceftazidime and Amikacin in one eye, and Cefazolin and Gentamicin in one eye. Intravitreal Dexamethasone injections were given to 69 eyes, $82 \%$. All eyes received topical antibiotics and steroids.

A comparison of culture-positive and culture-negative cases showed no significant difference in baseline demographics (Table 1). A greater number of culture-positive cases presented with a poor view of the fundus. The mean presenting intraocular pressure (IOP) was higher in culturepositive cases with no significant difference in final IOP. The mean pre-endophthalmitis VA showed no significant difference between groups, however mean presenting VA and 3-month $\log$ MAR $\Delta$ were worse in culture-positive cases (Figures 1 and 2).

Comparing Streptococcus cases with non-Streptococcus Gram-positive and coagulase-negative Staphylococcus cases showed no significant difference in baseline demographics (Table 2). The Streptococcus cases presented with a higher mean IOP and greater number of cases with a poor view of the fundus. A higher number of coagulase-negative Staphylococcus cases received tap and injection as the initial treatment. There was no significant difference in mean preendophthalmitis VA or presenting VA, however 3-month $\log$ MAR $\Delta$ was significantly worse in Streptococcus cases (Figure 3).

A comparison of Gram-negative cases with coagulase-negative Staphylococcus cases showed that fewer Gram-negative cases achieved VA $\geq 20 / 400$ at 3 months (Table 3). Pseudomonas and Serratia cases were associated with a poor view of the fundus, higher mean presenting IOP, and a worse 3-month $\log$ MAR $\Delta$ compared with coagulase-negative Staphylococcus cases. Pseudomonas and Serratia cases were also associated with a poor view of the fundus and worse 3-month $\log$ MAR $\Delta$ compared to Moraxella cases (Figure 4). 
Table I Culture-positive and culture-negative cases

\begin{tabular}{|c|c|c|}
\hline & Culture-positive & Culture-negative \\
\hline & $53 / 84(63 \%)$ & $31 / 84(37 \%)$ \\
\hline \multicolumn{3}{|l|}{ Age } \\
\hline Mean, SD & $75(12)$ & $71(13)$ \\
\hline \multicolumn{3}{|l|}{ Gender } \\
\hline Female & $26(50 \%)$ & 15 (48\%) \\
\hline Male & $26(50 \%)$ & $16(52 \%)$ \\
\hline \multicolumn{3}{|l|}{ Diabetes mellitus } \\
\hline Present & $6(12 \%)$ & $5(17 \%)$ \\
\hline Absent & $46(88 \%)$ & $25(83 \%)$ \\
\hline \multicolumn{3}{|l|}{ Antimetabolites } \\
\hline Used & $33(64 \%)$ & $20(69 \%)$ \\
\hline Not used & $19(36 \%)$ & $9(31 \%)$ \\
\hline \multicolumn{3}{|l|}{ Bleb leak } \\
\hline Present & $10(19 \%)$ & II (35\%) \\
\hline Absent & $43(81 \%)$ & $20(65 \%)$ \\
\hline $\begin{array}{l}\text { Mean time of onset of } \\
\text { endophthalmitis, SD }\end{array}$ & endophthalmitis, SD & 49 months (42) \\
\hline \multicolumn{3}{|l|}{ Anterior chamber } \\
\hline Hypopyon & $36(68 \%)$ & $23(74 \%)$ \\
\hline \multicolumn{3}{|l|}{ View to fundus } \\
\hline Hazy & $15(28 \%)$ & $15(48 \%)$ \\
\hline Poor/none & $38(72 \%)$ & $16(52 \%)$ \\
\hline \multicolumn{3}{|l|}{ Intraocular pressure } \\
\hline Presentation, SD & $24(15)$ & $14(9)^{*}$ \\
\hline \multicolumn{3}{|l|}{ Treatment, initial } \\
\hline Tap and injection & $30(57 \%)$ & $24(77 \%)$ \\
\hline Pars plana vitrectomy & $23(43 \%)$ & $7(23 \%)$ \\
\hline \multicolumn{3}{|l|}{ Treatment, additional } \\
\hline Filtering procedure & $7(13 \%)$ & $6(19 \%)$ \\
\hline Pars plana vitrectomy & $19(36 \%)$ & $5(16 \%)^{*}$ \\
\hline VA before endophthalmitis & $\mathrm{n}=50$ & $\mathrm{n}=3 \mathrm{l}$ \\
\hline Mean & $20 / 81$ & $20 / 95$ \\
\hline Range & 20/20-LP & $20 / 25-\mathrm{CF}$ \\
\hline Presenting VA & $\mathrm{n}=53$ & $\mathrm{n}=3 \mathrm{l}$ \\
\hline Mean & $0.7 / 200$ & $1.6 / 200 *$ \\
\hline Range & 20/40-NLP & 20/50-LP \\
\hline VA 3 months posttreatment & $\mathrm{n}=47$ & $\mathrm{n}=19$ \\
\hline Mean & $4.1 / 200$ & $20 / 209 *$ \\
\hline Range & $20 / 25-N L P$ & 20/25-LP \\
\hline $20 / 400$ or better & $26(55 \%)$ & $14(74 \%)$ \\
\hline LogMAR $\Delta$ & 1.03 & $0.43 *$ \\
\hline
\end{tabular}

Note: $* P \leq 0.05$, culture-positive compared to culture-negative cases.

Abbreviations: CF, counting fingers; LP, light perception; NLP, no light perception; $\mathrm{SD}$, standard deviation; VA, visual acuity.

Streptococcus and Serratia cases were associated with enucleation or evisceration (Table 4). Six of seven eyes that received an additional treatment of enucleation or evisceration had a culture result of Streptococcus or Serratia sp.

\section{Discussion}

The current study reports associations between culture results and clinical presentations and outcomes not clearly demonstrated in previous BAE series. The inability to detect these associations in past studies may have been due to the

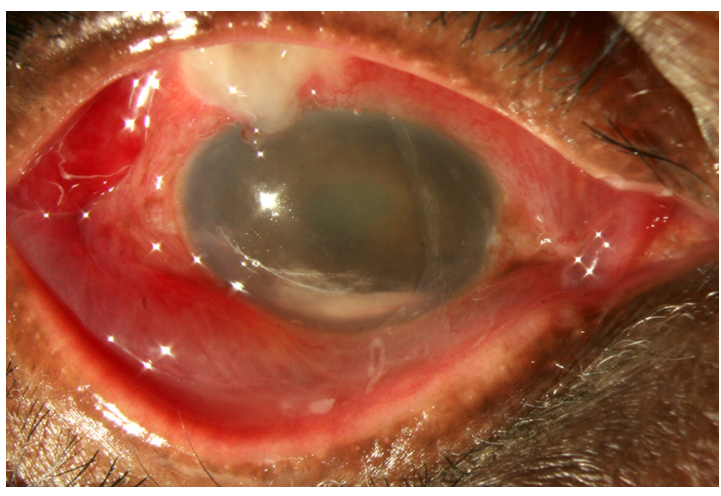

Figure I Photograph of right eye of 66-year-old male presenting with BAE from Streptococcus sp. Presenting VA: HM, IOP: $28 \mathrm{mmHg}$. Treatment: tap and injection. Final VA: HM, IOP: $12 \mathrm{mmHg}$. Culture-positive cases were associated with worse presenting $V A$ and higher presenting IOP than culture-negative cases.

Abbreviations: BAE, bleb-associated endophthalmitis; HM, hand motion; IOP, intraocular pressure; VA, visual acuity.

limited power inherent in smaller case series and the manner in which VA outcomes were analyzed. Previous BAE studies reported the percentage of eyes $\geq 20 / 400$ or the loss of $\geq 5$ Snellen lines. ${ }^{1-6}$ While this information is clinically descriptive, it may be limited for comparative purposes by the poor baseline VA of many glaucomatous eyes. Mean $\log$ MAR $\Delta$ more precisely measures VA outcomes in low vision eyes.

The broad groups of causative organisms used in past BAE case series may also have limited the ability to detect associations with VA outcomes. A previous BAE case series used the classification of non-Streptococcus Gram-positive organisms. ${ }^{2}$ Non-Streptococcus Gram-positive organisms include a wide range of organisms such as Staphylococcus aureus, Enterococcus, and coagulase-negative

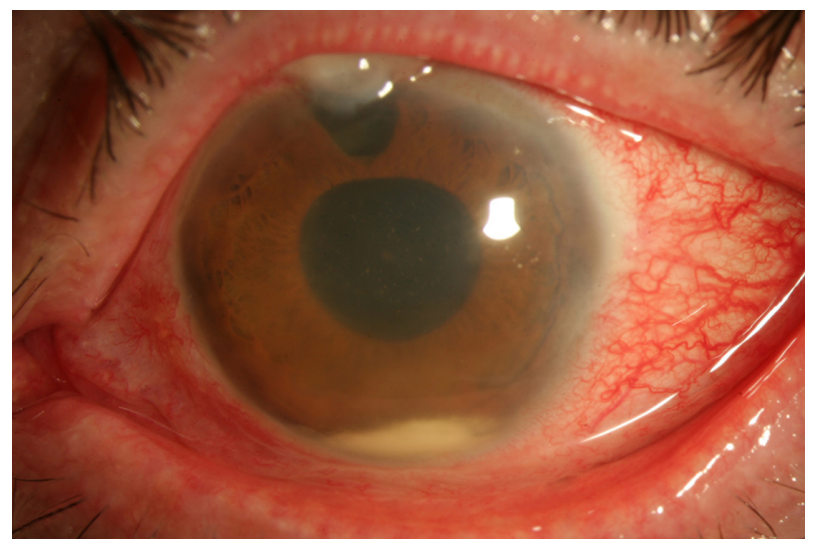

Figure 2 Photograph of left eye of 67-year-old male presenting with culturenegative BAE. Presenting VA: 20/200, IOP: $10 \mathrm{mmHg}$. Treatment: tap and injection. Final VA 20/200, IOP $16 \mathrm{mmHg}$. Culture-negative cases were associated with better VA outcomes than culture-positive cases.

Abbreviations: BAE, bleb-associated endophthalmitis; IOP, intraocular pressure; VA, visual acuity. 
Table 2 Gram-positive cases

\begin{tabular}{|c|c|c|c|c|}
\hline & Streptococcus & Non-Streptococcus & Coagulase-negative & Enterococcus \\
\hline & & Gram-positive & Staphylococcus & \\
\hline & $21 / 84(25 \%)$ & I7/84 (20\%) & $9 / 84(11 \%)$ & $6 / 84(7 \%)$ \\
\hline \multicolumn{5}{|l|}{ Age } \\
\hline Mean, SD & $72(14)$ & $77(8)$ & $77(9)$ & $76(9)$ \\
\hline \multicolumn{5}{|l|}{ Gender } \\
\hline Female & $9(45 \%)$ & $7(4 \mid \%)$ & $3(33 \%)$ & $3(50 \%)$ \\
\hline Male & II (55\%) & $10(59 \%)$ & $6(67 \%)$ & $3(50 \%)$ \\
\hline \multicolumn{5}{|l|}{ Diabetes mellitus } \\
\hline Present & $2(10 \%)$ & I (6\%) & I (II\%) & $0(0 \%)$ \\
\hline Absent & $18(90 \%)$ & $16(94 \%)$ & $8(89 \%)$ & $6(100 \%)$ \\
\hline \multicolumn{5}{|l|}{ Antimetabolites } \\
\hline Used & II (55\%) & 14 (82\%) & $9(100 \%)$ & $3(50 \%)$ \\
\hline Not used & $9(45 \%)$ & $3(18 \%)$ & $0(0 \%)$ & $3(50 \%)$ \\
\hline \multicolumn{5}{|l|}{ Bleb leak } \\
\hline Present & $4(19 \%)$ & $4(24 \%)$ & $3(33 \%)$ & I (I7\%) \\
\hline Absent & 17 (8I\%) & $13(76 \%)$ & $6(67 \%)$ & $4(67 \%)$ \\
\hline \multicolumn{5}{|l|}{ Anterior chamber } \\
\hline Hypopyon & II (52\%) & $13(77 \%)$ & 7 (78\%) & $4(67 \%)$ \\
\hline \multicolumn{5}{|l|}{ View to fundus } \\
\hline Hazy & $2(10 \%)$ & $9(53 \%)$ & $5(56 \%)$ & $2(33 \%)$ \\
\hline Poor/none & $19(90 \%)$ & $8(47 \%) *$ & $4(44 \%)^{\dagger}$ & $4(67 \%)$ \\
\hline Mean time of onset of endophthalmitis, SD & 7I months (40) & 64 months (57) & 57 months (58) & 77 months $(72)$ \\
\hline \multicolumn{5}{|l|}{ Intraocular pressure } \\
\hline Presentation, SD & $29(16)$ & $18(15)^{*}$ & $\mathrm{II}(8)^{\dagger}$ & $30(17)$ \\
\hline \multicolumn{5}{|l|}{ Treatment, initial } \\
\hline Tap and injection & $9(43 \%)$ & $12(7 \mid \%)$ & $8(89 \%)^{\dagger}$ & $3(50 \%)$ \\
\hline Pars plana vitrectomy & $12(57 \%)$ & $5(29 \%)$ & I (II\%) & $3(50 \%)$ \\
\hline \multicolumn{5}{|l|}{ Treatment, additional } \\
\hline Filtering procedure & $2(10 \%)$ & $5(29 \%)$ & $4(44 \%)^{\dagger}$ & $0(0 \%)$ \\
\hline Pars plana vitrectomy & $10(48 \%)$ & $3(18 \%)^{*}$ & $\mathrm{I}(\mathrm{II} \%)^{\dagger}$ & $2(33 \%)$ \\
\hline VA before endophthalmitis & $\mathrm{n}=19$ & $\mathrm{n}=17$ & $\mathrm{n}=9$ & $\mathrm{n}=6$ \\
\hline Mean & $20 / 62$ & $20 / 73$ & $20 / 54$ & $20 / 167$ \\
\hline Range & $20 / 20-4 / 200$ & 20/20-LP & $20 / 25-20 / 200$ & 20/25-LP \\
\hline Presenting VA & $\mathrm{n}=2 \mathrm{I}$ & $\mathrm{n}=17$ & $\mathrm{n}=9$ & $\mathrm{n}=6$ \\
\hline Mean & $0.5 / 200$ & $0.8 / 200$ & $1 / 200$ & $0.5 / 200$ \\
\hline Range & 20/40-LP & 20/80-NLP & 20/200-LP & 20/80-NLP \\
\hline VA 3 months posttreatment & $\mathrm{n}=20$ & $\mathrm{n}=14$ & $n=9$ & $\mathrm{n}=4$ \\
\hline Mean & $1.9 / 200$ & $20 / 209 *$ & $20 / 110^{+}$ & $3 / 200$ \\
\hline Range & 20/30-NLP & 20/25-LP & 20/25-HM & 20/100-LP \\
\hline $20 / 400$ or better & $9(45 \%)$ & II (79\%)* & $8(89 \%)^{\dagger}$ & $2(50 \%)$ \\
\hline LogMAR $\Delta$ & 1.44 & $0.46^{*}$ & $0.3 \mathrm{I}^{\dagger}$ & 0.89 \\
\hline
\end{tabular}

Notes: $* P \leq 0.05$, Streptococcus compared to non-Streptococcus Gram-positive cases; ${ }^{\dagger} P \leq 0.05$, Streptococcus compared to coagulase-negative Staphylococcus cases. Abbreviations: HM, hand motion; LP, light perception; NLP, no light perception; SD, standard deviation; VA, visual acuity.

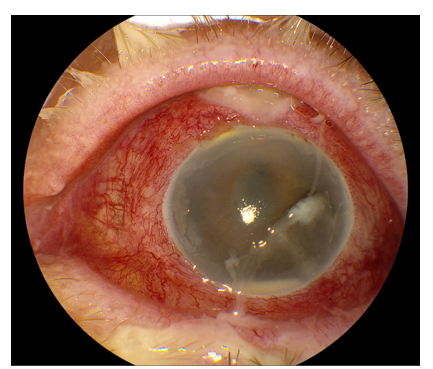

Figure 3 Photograph of left eye of 79-year-old female presenting with BAE from Streptococcus sp. Presenting VA: LP, IOP: $40 \mathrm{mmHg}$. Treatment: pars plana vitrectomy. Final VA: LP, IOP: $0 \mathrm{mmHg}$. Only $45 \%$ of Streptococcus cases had VA outcomes $\geq 20 / 400$.

Abbreviations: BAE, bleb-associated endophthalmitis; IOP, intraocular pressure; LP, light perception; VA, visual acuity.
Staphylococcus cases that have varying VA outcomes. The current study narrowed the analysis to individual causative organisms, strengthening associations with VA outcomes.

An analysis of Gram-negative cases by individual organism showed that Pseudomonas and Serratia cases had worse mean VA outcomes than Moraxella cases. The relatively good VA outcomes of Moraxella cases, $71 \% \geq 20 / 400$, confirms the previous report by Berrocal et al of favorable outcomes with Moraxella cases. ${ }^{11}$

The current study also provides insight into the clinical presentation of causative organisms in BAE. Streptococcus, Pseudomonas, and Serratia cases were associated with 
Table 3 Gram-negative cases

\begin{tabular}{|c|c|c|c|c|}
\hline & Gram-negative & Moraxella & Pseudomonas & Serratia \\
\hline & $15 / 84(18 \%)$ & $8 / 84(10 \%)$ & $3 / 84(4 \%)$ & $3 / 84(4 \%)$ \\
\hline \multicolumn{5}{|l|}{ Age } \\
\hline Mean, SD & $78(14)$ & $72(I I)$ & $82(18)$ & $89(12)$ \\
\hline \multicolumn{5}{|l|}{ Gender } \\
\hline Female & $10(67 \%)$ & $4(50 \%)$ & $3(100 \%)$ & $2(67 \%)$ \\
\hline Male & $5(33 \%)$ & $4(50 \%)$ & $0(0 \%)$ & I (33\%) \\
\hline \multicolumn{5}{|l|}{ Diabetes mellitus } \\
\hline Present & $3(20 \%)$ & $2(25 \%)$ & I (33\%) & $0(0 \%)$ \\
\hline Absent & $12(80 \%)$ & $6(75 \%)$ & $2(67 \%)$ & $3(100 \%)$ \\
\hline \multicolumn{5}{|l|}{ Antimetabolites } \\
\hline Used & $8(53 \%)$ & $5(63 \%)$ & I (33\%) & $2(67 \%)$ \\
\hline Not used & $7(47 \%)$ & $3(37 \%)$ & $2(67 \%)$ & I (33\%) \\
\hline \multicolumn{5}{|l|}{ Bleb leak } \\
\hline Present & $2(13 \%)$ & $2(75 \%)$ & $0(0 \%)$ & $0(0 \%)$ \\
\hline Absent & $13(87 \%)$ & $6(75 \%)$ & $3(100 \%)$ & $3(100 \%)$ \\
\hline \multicolumn{5}{|l|}{ Anterior chamber } \\
\hline Hypopyon & $12(80 \%)$ & $6(75 \%)$ & $2(67 \%)$ & $3(100 \%)$ \\
\hline \multicolumn{5}{|l|}{ View to fundus } \\
\hline Hazy & $4(27 \%)$ & $4(50 \%)$ & $0(0 \%)$ & $0(0 \%)$ \\
\hline Poor/none & II (73\%) & $4(50 \%)^{\dagger}$ & $3(100 \%)$ & $3(100 \%)^{\ddagger}$ \\
\hline Mean time of onset of endophthalmitis, SD & 51 months (36) & 56 months (32) & 57 months (77) & 34 months (38) \\
\hline \multicolumn{5}{|l|}{ Intraocular pressure } \\
\hline Presentation, SD & $22(12)^{*}$ & $23(15)$ & $26(12)$ & $18(4)^{\ddagger}$ \\
\hline \multicolumn{5}{|l|}{ Treatment, initial } \\
\hline Tap and injection & $9(60 \%)$ & $5(63 \%)$ & I (33\%) & $2(67 \%)$ \\
\hline Pars plana vitrectomy & $6(40 \%)$ & $3(37 \%)$ & $2(67 \%)$ & I (33\%) \\
\hline \multicolumn{5}{|l|}{ Treatment, additional } \\
\hline Filtering procedure & $0(0 \%)$ & $0(0 \%)$ & $0(0 \%)$ & $0(0 \%)$ \\
\hline Pars plana vitrectomy & $6(40 \%)^{*}$ & $4(50 \%)^{\dagger}$ & $0(0 \%)$ & I (33\%) \\
\hline VA before endophthalmitis & $\mathrm{n}=14$ & $\mathrm{n}=7$ & $\mathrm{n}=3$ & $\mathrm{n}=3$ \\
\hline Mean & $20 /|3|$ & $20 / 194$ & $20 / 14 \mid$ & $20 / 74$ \\
\hline Range & 20/25-HM & 20/25-HM & $20 / 40-4 / 200$ & $20 / 50-20 / 100$ \\
\hline Presenting VA & $\mathrm{n}=15$ & $\mathrm{n}=8$ & $\mathrm{n}=3$ & $\mathrm{n}=3$ \\
\hline Mean & $0.9 / 200$ & $1.4 / 200$ & $1.6 / 200$ & LP \\
\hline Range & 20/80-LP & 20/80-LP & $20 / 100-\mathrm{LP}$ & HM-LP \\
\hline VA 3 months posttreatment & $\mathrm{n}=13$ & $n=7$ & $\mathrm{n}=2$ & $\mathrm{n}=3$ \\
\hline Mean & $2.5 / 200 *$ & $20 / 264^{\dagger}$ & LP & LP $\ddagger$ \\
\hline Range & 20/40-NLP & 20/40-HM & LP-LP & LP-NLP \\
\hline $20 / 400$ or better & $6(46 \%)^{*}$ & $5(7 \mid \%)^{\dagger}$ & $0(0 \%)$ & $0(0 \%)^{\ddagger}$ \\
\hline LogMAR $\Delta$ & 1.08 & $0.04^{\dagger}$ & 1.88 & $2.77^{\ddagger}$ \\
\hline
\end{tabular}

Note: $* P \leq 0.05$, Gram-negative compared to coagulase-negative Staphylococcus cases. ${ }^{\dagger} P \leq 0.05$, Pseudomonas and Serratia compared to Moraxella cases. $\ddagger P \leq 0.05$, Pseudomonas and Serratia compared to coagulase-negative Staphylococcus cases.

Abbreviations: HM, hand motion; LP, light perception; NLP, no light perception; SD, standard deviation; VA, visual acuity.

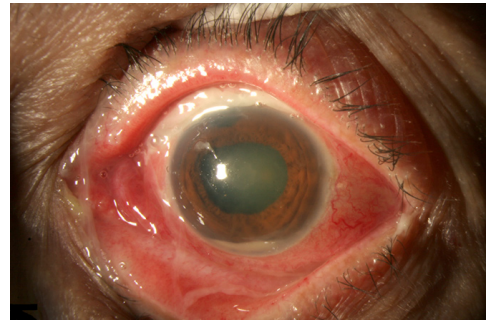

Figure 4 Photograph of left eye of 72-year-old female with BAE from Moraxella sp. Presenting VA: I/200, IOP: $35 \mathrm{mmHg}$. Treatment: tap and injection. Final VA: 20/25, IOP: I I mmHg. Moraxella cases were associated with a better presenting view of the fundus and better VA outcomes than Pseudomonas and Serratia cases.

Abbreviations: BAE, bleb-associated endophthalmitis; IOP, intraocular pressure; VA, visual acuity. a higher mean IOP and worse view of the fundus than coagulase-negative Staphylococcus cases. Similarly culture positive cases were associated with a worse presenting VA and higher presenting IOP than culture negative cases. The clinician can consider the increased likelihood of a more virulent organism and worse visual prognosis when the patient presents with poor VA, high IOP, and poor view of the fundus.

The VA outcome analysis provided in this study confirms what clinicians have suspected for decades. Worse VA outcomes in BAE are associated with the most frequent isolates, Streptococcus sp. and Gram-negative organisms such as 
Table 4 Enucleation or evisceration in nine eyes (10\%)

\begin{tabular}{|c|c|c|c|}
\hline Case \# & Culture result & Initial treatment & Additional treatment \\
\hline 5 & Serratia and Streptococcus & T\&I & Enucleation \\
\hline 17 & Serratia & $\mathrm{T} \& \mathbf{I}$ & Enucleation \\
\hline 33 & Serratia & PPV & Evisceration \\
\hline 26 & Streptococcus & T\&I & Evisceration \\
\hline 37 & Streptococcus & PPV & Enucleation \\
\hline 43 & Streptococcus & PPV & Enucleation \\
\hline 46 & No growth & PPV & Evisceration \\
\hline 25 & Not done & Evisceration & \\
\hline 70 & Not done & Evisceration & \\
\hline
\end{tabular}

Note: $P=0.01$, Enucleation or evisceration for Streptococcus or Serratia compared with other culture results.

Abbreviations: PPV, Pars planavitrectomy; T\&l, tap and injection.

Pseudomonas and Serratia sp. When discussing prognosis, clinicians may consider that eyes with Streptococcus sp. and Gram-negative organisms had VA outcomes $\geq 20 / 400$ in only $45 \%$ and $46 \%$ of cases respectively while eyes with coagulase-negative Staphylococcus sp. Achieved $\geq 20 / 400$ in $89 \%$ of cases.

Interestingly coagulase-negative Staphylococcus cases achieved better VA outcomes despite less aggressive treatment. Only $11 \%$ of the coagulase-negative Staphylococcus cases received pars plana vitrectomy compared with 57\% of the Streptococcus cases. The higher mean IOP and worse view of the fundus in the Streptococcus cases likely compelled the treating clinician to more frequently favor pars plana vitrectomy. The role pars plana vitrectomy plays in BAE can only be determined by a sufficiently powered prospective randomized control trial. Unfortunately this may not be feasible due to the limited number of BAE cases.

The current study was not designed to determine the best management for BAE, but it does provide insight into the key role causative organisms play in the clinical presentation and prognosis of BAE. Culture-positive cases were associated with worse presenting VA, higher presenting IOP, and worse VA outcomes than culture-negative cases. Streptococcus, Pseudomonas, and Serratia cases were associated with poor presenting view of the fundus and worse VA outcomes than coagulase-negative Staphylococcus and Moraxella cases.

Clinical Ophthalmology

\section{Publish your work in this journal}

Clinical Ophthalmology is an international, peer-reviewed journal covering all subspecialties within ophthalmology. Key topics include: Optometry; Visual science; Pharmacology and drug therapy in eye diseases; Basic Sciences; Primary and Secondary eye care; Patient Safety and Quality of Care Improvements. This journal is indexed on Submit your manuscript here: http://www.dovepress.com/clinical-ophthalmology-journal

\section{Disclosure}

No conflicts of interest were declared in relation to this paper.

\section{References}

1. Leng T, Miller D, Flynn HW Jr, Jacobs DJ, Gedde SJ. Delayed-onset bleb-associated endophthalmitis (1996-2008): causative organisms and visual acuity outcomes. Retina. September 10, 2010. [Epub ahead of print]

2. Busbee BG, Recchia FM, Kaiser R, Nagra P, Rosenblatt B, Pearlman RB. Bleb-associated endophthalmitis: clinical characteristics and visual outcomes. Ophthalmology. 2004;111(8):1495-1503; discussion 1503.

3. Ba'arah BT, Smiddy WE. Bleb-related endophthalmitis: clinical presentation, isolates, treatment and visual outcome of culture-proven cases. Middle East Afr J Ophthalmol. 2009;16(1):20-24.

4. Kangas TA, Greenfield DS, Flynn HW Jr, Parrish RK 2nd, Palmberg P. Delayed-onset endophthalmitis associated with conjunctival filtering blebs. Ophthalmology. 1997;104(5):746-752.

5. Mandelbaum S, Forster RK, Gelender H, Culbertson W. Late onset endophthalmitis associated with filtering blebs. Ophthalmology. 1985;92(7):964-972.

6. Song A, Scott IU, Flynn HW Jr, Budenz DL. Delayed-onset blebassociated endophthalmitis: clinical features and visual acuity outcomes. Ophthalmology. 2002;109(5):985-991.

7. Ciulla TA, Beck AD, Topping TM, Baker AS. Blebitis, early endophthalmitis, and late endophthalmitis after glaucoma-filtering surgery. Ophthalmology. 1997;104(6):986-995.

8. Ciulla TA, Baker AS. Endophthalmitis following glaucoma filtering surgery. Int Ophthalmol Clin. 1996;36(3):87-96.

9. Poulsen EJ, Allingham RR. Characteristics and risk factors of infections after glaucoma filtering surgery. J Glaucoma. 2000;9(6):438-443.

10. Sharan S, Trope GE, Chipman M, Buys YM. Late-onset bleb infections: prevalence and risk factors. Can J Ophthalmol. 2009;44(3): 279-283.

11. Berrocal AM, Scott IU, Miller D, Flynn HW Jr. Endophthalmitis caused by Moraxella species. Am J Ophthalmol. 2001;132(5):788-790.

\section{Dovepress}

PubMed Central and CAS, and is the official journal of The Society of Clinical Ophthalmology (SCO). The manuscript management system is completely online and includes a very quick and fair peer-review system, which is all easy to use. Visit http://www.dovepress.com/ testimonials.php to read real quotes from published authors. 